\title{
PEMILIHAN KAWASAN WISATA KULINER SEBAGAI DAYA TARIK WISATA DI KOTA BOGOR (Studi Kasus : Kawasan Kuliner Bogor Utara).
}

\author{
Clara Mutiara, Riza Firmansyah \\ Program Studi Pariwisata Fakultas Pariwisata Universitas Pancasila \\ Jl. Serengseng Sawah, Jagakarsa, Jakarta Selatan 12640
}

\begin{abstract}
Bogor Barat Culinary Area is a culinary area with the most restaurants in the cityof Bogor. It can be known that currently there are approximately 65 restaurants in North Bogor. This area is quite strategic and islocated on the trade route that has been planned by the Bogor City Government, this is the big opportunity for North Bogor Region as the biggestculinary area in th ecity of Bogor. In this study the concept of culinary tourism was used to analyze several restaurants with the concept of culinary tourism seen from the Menu, Food Production Strategy, Service, Price and Room Decor I Atmosphere by taking a sample of 10 restaurants in North Bogor, including : Ayam Geprek Istimewa, Bakso Misterius, Bumi Aki, Foresthree Resto, Gurih 7, Lemongrass Resto, Teras Dara, Whatever Resto dan Warung Urban.The purpose of this study is to analyze the existing conditions of culinary tourism in North Bogor and analyze the selection of restaurants in North Bogor. The design of this study uses a descriptive approach with qualitative methods. For the selection of culinary tourism area, it uses AHP analysis to find out which culinary tourism concept is more desirable and what restaurant is the priority. To find out the development strategy of North Bogor culinary area with a SWOT analysis.
\end{abstract}

Keywords: North Bogor Culinary Area, ConceptofCulinary Tourism, Region Selection, Development Strategy.

\section{PENDAHULUAN}

Kota Bogor sedang berada ditahap berkembang salah satunya yang cukup terlihat yaitu wisata kuliner yang berada di Kota Bogor bermunculan. Baik itu kuliner tradisional ataupun kuliner yang berasal dari internasional. Tak hanya wisata kulier saja melainkan seperti Taman Kota dan Factory Outlet pun menjadi perhatian masyarakat tidak hanya yang berdomisili Kota Bogor saja akan tetapi masyarakat yang berdomisili di Jabodetabek. Mulyana (2011) menyatakan bahwa keberadaan letaknya yang strategis merupakan potensi untuk pengembangan pembangunan, pertumbuhan ekonomi dan pelayanan, pusat industri nasional, perdagangan, transportasi, komunikasi dan pariwisata.

Pemerintah memperoleh pendapatan dari sektor pariwisata dari beberapa cara.

Sumbangan pendapatan terbesar dari pariwisata bersumber dari pengenaan pajak. Misalnya, pengenaan pajak hotel dan restoran yang merupakan bagian dari keuntungan usaha pariwisata hotel dan restoran tersebut. Sumber lain bisa berupa usaha pariwisata yang dimiliki oleh pemerintah daerah sendiri. Kartini (2011) mengungkapkan pemerintah daerah juga mengenakan pajak secara langsung kepada wisatawan jika mereka melakukan transaksi yang tergolong kena pajak. Biasanya dikenal sebagai service tax, yang umumnya sebesar $10 \%$ untuk transaksi di hotel dan restoran. Pajak ini berbeda dari pajak yang sumbernya dari keuntungan hotel dan restoran yang diberikan sebelumnya.

Tabel 1.1 Jumlah Kunjungan Wisatawan Kota Bogor

\begin{tabular}{|l|l|l|l|l|}
\hline No & Tahun & $\begin{array}{c}\text { Wisatawan } \\
\text { Nusantara }\end{array}$ & $\begin{array}{c}\text { Wisatawan } \\
\text { Mancanegara }\end{array}$ & Jumlah \\
\hline 1 & 2014 & 4.146 .766 & 202.187 & 4.348 .953 \\
\hline 2 & 2015 & 4.561 .443 & 222.406 & 4.783 .848 \\
\hline 3 & 2016 & 5.017 .587 & 244.646 & 5.262 .224 \\
\hline
\end{tabular}

Sumber: Dinas Pariwisata dan Kebudayaan Kota Bogor

Wisata kuliner di Kota Bogor pada saat ini cukup menarik perhatian wisatawan yang datang. Baik wisatawan yang merencanakan datang ke Kota Bogor untuk wisata kuliner ataupun wisatawan yang tidak merencanakan untuk wisata kuliner dengan tujuan utamanya untuk bisnis, berobat dan sebagainya. Menurut hasil dari laporan BPS Kota Bogor data yang ada di BPS saja tidak kurang terdapat sekitar 45 hotel, penginapan, wisma maupun guest house yang ada di Kota Bogor. Belum dari jenis usaha turunannya seperti restoran, cafe, hingga lokasi tujuan wisata yang tentunya 
menarik banyak orang untuk datang. Tak hanya wisatawan, tapi juga para pebisnis.

Alasan mengapa menjadikan Bogor Utara Kota Bogor menjadi lokasi khusus dalam penelitian ini adalah dikarenakan dilihat dari jumlah rumah makan yang berada di kawasan tersebut tercatat ada 65 rumah makan menurut BPS Kota Bogor 2017. Yang jumlahnya lebih banyak dibandingkan kawasan kuliner Kota Bogor yang lainnya. Setelah itu dikawasan tersebut saat ini sedang bermunculan rumah makan yang memiliki dekorasi ataupun tema yang unik sehingga menambah warna pada kawasan wisata kuliner di Bogor Utara Kota Bogor.

Pada penelitian ini di fokuskan kepada 10 rumah makan yang ada di Kawasan Bogor Utara, antara lain Ayam Geprek Istimewa, Bakso Misterius, Bumi Aki, Death By Chocolate, Foresthree Resto, Lemongrass Resto, Teras Dara, Whatever Resto, Warung Urban. Dari 10 sampel yang di pilih merupakan rumah makan yang memenuhi kriteria dari konsep wisata kuliner seperti: Menu, Strategi Produksi Makanan, Pelayanan, Harga dan Dekorasi/Suasana Ruang. Hal tersebut yang membuat peneliti ini memilih 10 rumah makan tersebut sebagai fokus utama lokasi penelitian ini. Dengan contoh seperti pada rumah makan Ayam Geprek Istimewa ini memiliki semua konsep wisata kuliner seperti Menu, Strategi Produksi Makanan, Pelayanan, Harga dan Dekorasi. Hal tersebut yang menjadikan rumah makan tersebut dipilih sebagai salah satu rumah makan yang menjadi lokasi fokus penelitian.

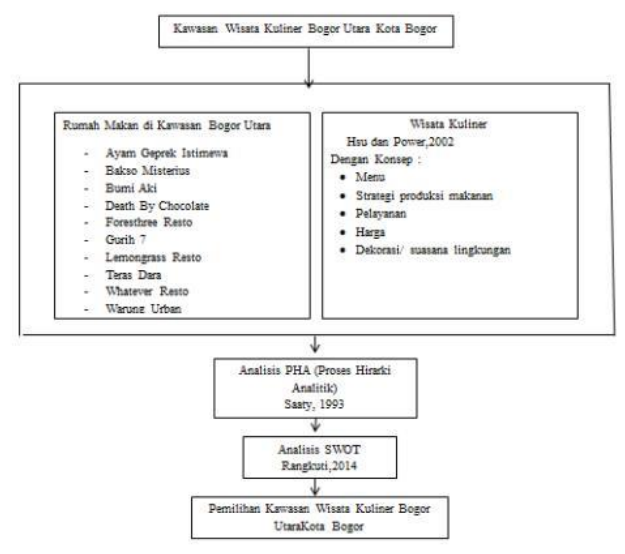

Gambar 1 Kerangka Pemikiran
Hsu dan Power (2002) dalam Aldof Ostaf menyatakan bahwa konsep bisnis kuliner terdiri dari lima elemen yaitu:

1. Menu

Konsep elemen ini meliputi restoran mulai dari yang menawarkan satu jenis menu (hidangan), seperti restoran eskrim, restoran kue donat, sampai kepada restoran yang menawarkan menu atau hidangan lengkap yang terdiri dari hidangan pembuka, sup, hidangan utama dan hidangan penutup.

2. Strategi produksi makanan

Beberapa restoran menawarkan hidangan yang cepat saji, seperti hamburger,

kentang goreng, dan sandwich, sedangkan restoran lainnya menawarkan makanan yang memerlukan pengolahan lama dan rumit seperti pada jenis restoran klasik.

3. Pelayanan

Pelayanan di restoran sangat bervariasi tergantung dari jenis restoran tersebut. Ada restoranyang menawarkan makanan pelayanan formal atau mewah, dan ada restoran yang menawarkan pelayanan sederhana seperti pelayanan prasmanan. Menurut Saputra (2014) pelayanan merupakan salah satu faktor penting dalam usaha mencapai keunggulan bersaing, untuk mencapai kualitas jasa yangdiinginkan,pengelolajasa

memerlukan upaya pemenuhan keinginan konsumen serta penyampaian yang tepat untuk memenuhi keinginan konsumen. Kualitas layanan merupakan bentuk penilaian konsumen terhadap tingkat layanan yang diterima (perceived service) dengan tingkat pelayanan yang diharapkan expected service. Definisi kualitas jasa pelayanan berfokus pada upaya pemenuhan kebutuhan dan keinginan pelanggan serta ketepatan penyampaiannya untuk mengimbangi harapan pelanggan.

Macam-macam pelayanan menurut Puspoyo et al (2015):

a. Self service

Yaitu sistem pelayanan dimana pengunjung melakukan pelayanan untuk dirinya sendiri. Cara ini

berkesan familiar karena pengunjung datang mengambil makanan dan minuman yang mereka inginkan, kemudian menuju ke kasir untuk membayar. Setelah itu mereka dapat duduk ditempat yang telah disediakan.

b. Waiter or waitress to tables 
Yaitu sistem pelayanan dimana pengunjung yang datang dan duduk ditempat yang telah

disediakan dilayani oleh pramusaji. Cara ini berkesan lebih formal karena pramusaji melayani mulai dari pencatatan menu

hingga mengantarkan bon pembayaran kepada pengunjung.

c. Counter service

Yaitu sistem pelayanan dimana terdapat area khusus untuk display makanan yang ada dan

biasanya digunakan untuk pelayanan yang cepat. Cara ini berkesan tidak formal.

b. Automatic vending

Yaitu sistem pelayanan yang menggunakan mesin otomatis. Pengunjung memasukan koin lalu mesin mengeluarkan makanan yang dipesan.

4. Harga

Harga yang ditawarkan oleh restoran sangat bervariasi. Ada restoran yang menawarkan harga hidangan murah, sedang, dan ada restoran yang menawarkan harga mahal. Menurut Swastha (2010) dalam Riyono (2016) Harga adalah jumlah uang (ditambah beberapa barang kalau mungkin ) yang dibutuhkan untuk mendapatkan sejumlah kombinasi dari barang beserta pelayanannya . Menurut pendapat Riyono (2016) menjelaskan bahwa harga adalah unsur penting dalam sebuah peusahaan dimana dengan adanya harga maka perusahaan akan mendapatkan income bagi keberlangsungan perusahaan. Selain itu, harga juga merupakan alat yang nantinya dijadikan proses pertukaran terhadap suatu barang atau jasa oleh konsumen.

5. Dekorasi, Suasana lingkungan

Dekorasi atau suasana lingkungan yang ditawarkan oleh restoran sangat bervariasi, tergantung dari tema restoran itu sendiri. Ada restoran yang menawarkan suasana romantis, suasana santai, suasana mewah, atau yang suasananya menampilkan ciri khas suatu daerah atau negara.

\section{METODE}

Penelitian ini bersifat deskriptif kualitatif. Bersifat deskriptif yaitu suatu metode penelitian yang berusaha mendeskripsikan atau menggambarkan /melukiskan fenomena atau hubungan antar fenomena yang diteliti dengan sistematis, faktual dan akurat Natsir(1998) dalam Unga (2011). Penelitian deskriptif digunakan bertujuan agar peneliti dapat menggambarkan dengan lebih baik sifat-sifat yang diketahui keberadaannya serta relevan dengan variable-variabel yang diteliti. Pendekatan dalam penelitian ini merupakan pendekatan kualitatif untuk menggambarkan tanggapan responden tehadap obyek berdasarkan kuesioner yang diberikan.

Jenis data yang digunakan adalah data primer dan sekunder. Data Primer adalah data yang diperoleh langsung dari informan, dengan melakukan wawancara langsung dengan pengelola tempat kuliner dan wisatawan yang datang ke berbagai tempat kuliner yang berada di Kawasan Bogor Utara Kota Bogor. Data Sekunder adalah data yang diperoleh secara tidak langsung melalui bukubuku, dokumentasi, artikel, jurnal yang terkait dengan penelitian.

Jumlah sampel yang digunakan pada penelitian ini adalah sebanyak 30 sampel dengan 30 responden untuk 10 rumah makan yang menjadi fokus penelitian. Dalam proses penelitian ini, reponden yang dipilih secara purposive sampling.

Dalam penelitian kualitatif dan deskriptif . Teknik analisis yang akan digunakan dalam penyusunan Pemilihan Lokasi Wisata Kuliner Sebagai Daya Tarik Wisata di Kota Bogoryaitu dengan menelaah semua data-data yang diperoleh dari berbagai sumber, baik dari hasil kuesioner, wawancara langsung, pengamatan di lapangan, dokumen pribadi dan dokumen resmi. Analisis kualitatif dilakuakan secara deskriptif berdasarkan hasil kuantitatif. Data-data yang ada diproses melalui pengelompokkan data. Setelah itu melakukan penyusunan strategi dengan menggunakan analisis AHP serta semua elemen dalam AHP akan dijaring melalui jawaban responden terhadap pertanyaan yang diajukan. Setelah mendapatkan prioritas lalu dilakukan analisa

SWOT untuk mengetahui bagaimana kekuatan,kelemahan,peluang dan ancaman tersebut.

\section{HASIL PEMBAHASAN}

Data dibawah ini merupakan data dari hasil perhitungan AHP dengan menggunakan Expert Choice sebagai aplikasi pembantu guna

mempermudah perhitungan. Berikut merupakan hasil dari matriks perbandingan berpasangan antara kriteria: Menu, Strategi Produksi Makanan, Pelayanan, Harga, Dekorasi/ Suasana Ruang. Dengan alternatif : 
antara lain Ayam Geprek Istimewa, Bakso Misterius, Bumi Aki, Death By Chocolate, Foresthree Resto, Lemongrass Resto, Teras Dara, Whatever Resto, Warung Urban.
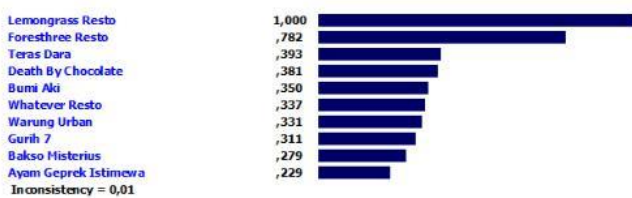

Gambar 2 Kriteria Menu Terhadap 10 Alternatif

Lemongrass Resto merupakan rumah makan yang lebih diminati dari segi menu yang ditawarkan. Dapat dilihat bahwa rumah makan ini memiliki nilai sebersar 1,000 dan yang terendah yaitu Ayam Geprek Istimewa dengan nilai 0,229
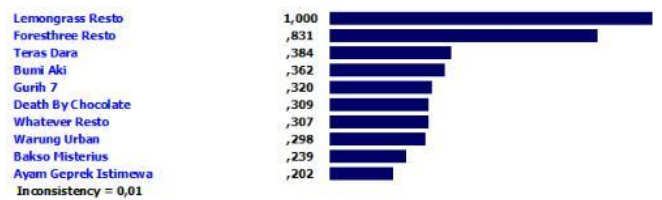

Gambar 3 Kriteria Strategi Produksi Makanan pada 10 Alternatif

Pada kriteria ini terlihat bahwa memang Lemongrass Resto ini memiliki standar produksi makanan yang lebih diminati dibandingkan dengan 9 alternatif lainnya dengan nilai 1,000. Dan Ayam Geprek Istimewa menempati posisi akhir dengan nilai 0,202 .
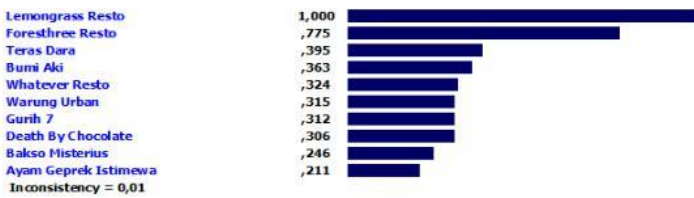

Gambar 4 Kriteria Pelayanan pada 10 Alternatif

Dapat dilihat bahwa memang Lemongrass Resto memiliki standar pelayanan yang memang diminati oleh wisatawan yang berkunjung. Hal ini menjadikan Lemongrass Resto menempati posisi utama dengan nilai 1,000 dan di posisi terendah terdapat Ayam Geprek Istimewa dengan nilai 0,211.
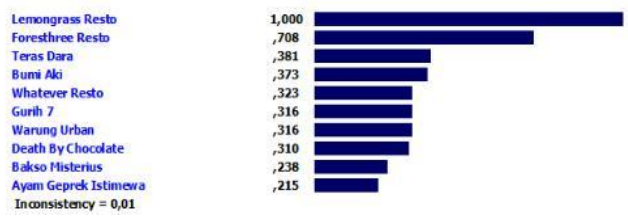

Gambar 5 Kriteria Harga pada 10 Alternatif

Lemongrass Resto berada pada posisi unggul dengan nilai 1,000 hal ini dilihat melalui hasil kriteria menu yang dibandingkan dengan 9 rumah makan yang ada.
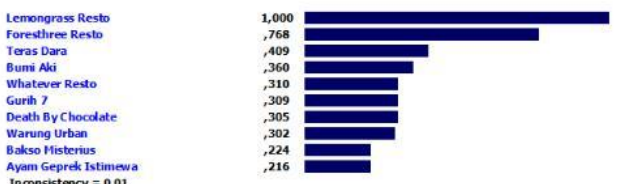

Gambar 6 Kriteria Dekorasi/Suasana Ruang pada 10 Alternatif

Pada kriteria dekorasi ini terlihat bahwa rumah makan Lemongrass Resto memiliki dekorasi yang memang nyaman dan diminati oleh wisatawan yang datang hal tersebut yang menjadikan rumah makan ini menjadi posisi utama pada perbandingan berpasangan ini.

Secara keseluruhan pada kriteria di penelitian ini wisatawan cenderung lebih minat terhadap Dekorasi/suasana ruang yang terlebih dahulu dipertimbangkan untuk memilih rumah makan di bandingkan dengan Strategi Produksi Makanan, Pelayanan, Harga dan Menu. Dapat dilihat bahwa Dekorasi berada pada urutan pertama dengan nilai 1,000 sedangkan untuk di urutan terakhir terdapat Strategi Produksi Makanan. Hal tersebut mengapa terjadi bukan karena Strategi Produksi Makanan tidak penting melainkan wisatawan cenderung lebih memilih dekorasi dibandingkan dengan kriteria lainnya. Hasil tersebut dapat dilihat dari gambar dibawah ini.
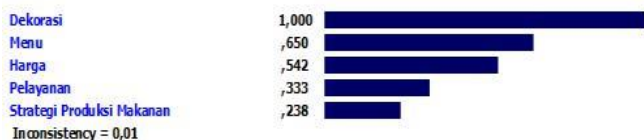

Gambar 7 Hasil Prioritas pada Kriteria

Pada penelitian ini pula harus mengetahui sekiranya rumah makan yang seperti apa yang menjadi incaran wisatawan atau standar rumah makan yang harus dijadika acuan oleh rumah makan lainnya dari segi Menu, Strategi Produksi Makanan, Pelayanan, Harga, Dekorasi/Suasana Ruang. Pada penelitian ini memfokuskan pada 10 rumah makan yang berada di kawasan Bogor Utara. Secara keseluruhan dari hasil penelitian tersebut dapat diambil kesimpulan bahwa Lemongrass Resto merupakan rumah makan yang memiliki standar dari segi Menu, Strategi Produksi Makanan, Pelayanan, Harga, Dekorasi/ Suasana Ruang yang diminati oleh wisatawan yang hendak berwisata kuliner khususnya pada Kawasan Kuliner Bogor Utara yang menjadi hasil prioritas pada analisis AHP ini. 


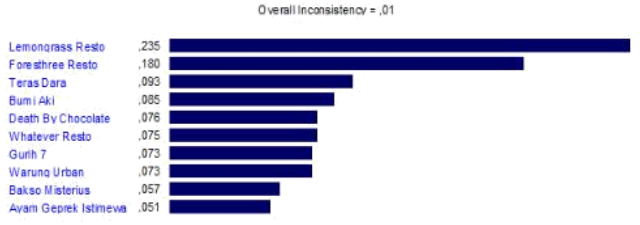

Gambar 8 Hasil Prioritas di Kawasan Kuliner Bogor Utara

Inconsistency (CR) keseluruhan pada analisis ini yaitu sebesar 0,01 yang dapat diartikan bahwa penelitian ini bersifat konsisten. Apabila nilai CR yang di dapatkan lebih dari 0,1 maka penelitian perlu diulang.

Hasil analisis mengunakan analisis SWOT Secara keseluruhan dari sampel yang ada dekorasi merupakan hal yang paling diminati dan menjadi salah satu daya tarik untuk mengunjungi rumah makan yang ada khususnya di Kawasan Bogor Utara, pada posisi kedua yang paling diminati adalah menu, posisi ketiga yaitu harga, posisi keempat adalah pelayanan dan posisi kelima yaitu strategi produksi makanan. Pada penelitian ini telah didapatkan lokasi yang menjadi prioritas di kawasan wisata kuliner Bogor Utara dari hasil pernelitian dengan menggunakan metode AHP. Namun dilakukan penelitian lanjutan dengan menggunakan analisis SWOT ini dengan menganalisis apa

saja Kekuatan (Strength), Kelemahan (Weakness), Peluang (Opportunities) dan Ancaman (Threats) yang ada di Kawasan Bogor Utara. Ditentukan berapa bobot masing masing point tersebut dan membuat matriks SWOT.

\section{Tabel 2. Matriks SWOT}

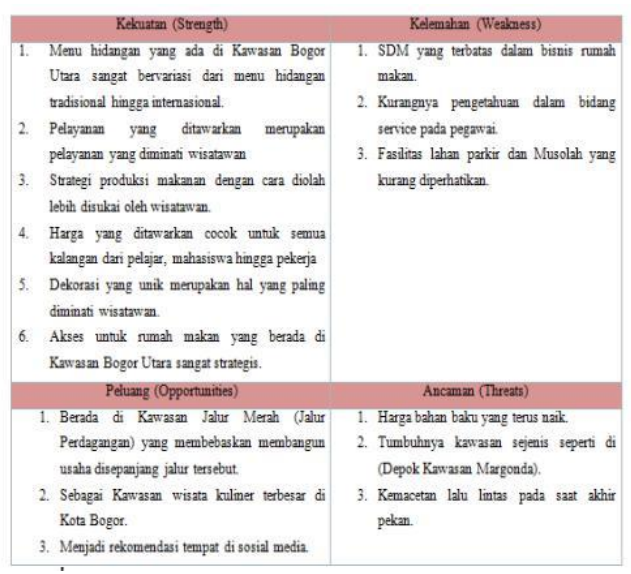

Sumber : Hasil Penelitian, 2018

Setelah melakukan identifikasi pada faktor internal dan eksternal maka selanjutnya adalah pemberian nilai berdasarkan tingkat kepentingan (bobot) yang dapat dilihat dalam matriks IFE (Internal Factor Evaluation) tabel 4.5dan EFE (Eksternal Faktor Evaluation) pada tabel 4.6 dibawah ini untuk mendapatkan hasil dari bobot dan rating tersebut merupakan hasil dari wawancara dan observsi peneliti terhadap responden yang berada di rumah makan pada kawasan Bogor Utara tersebut.

Tabel 3 Matrik IFE (Internal Factor Evaluation)

\begin{tabular}{|c|c|c|c|c|}
\hline $\mathrm{N}_{0}$ & $\begin{array}{l}\text { Faktor Internal } \\
\text { Falktor Kekuatan (Strength) }\end{array}$ & Bobot & Rating & Skor \\
\hline 1 & $\begin{array}{l}\text { Menu hidangan yang ada di Kawasan } \\
\text { Bogor Utara sangat bervariasi dari } \\
\text { manu hidangan tradisional hingga } \\
\text { intemasional. }\end{array}$ & 0,13 & 3 & 0,39 \\
\hline 2 & $\begin{array}{l}\text { Pelayanan yang ditawrerkan } \\
\text { merupakan polayanan yang diminati } \\
\text { wisatawan }\end{array}$ & 0,10 & 2 & 0,20 \\
\hline 3 & $\begin{array}{l}\text { Strategi produlksi maksanan dengan } \\
\text { cara diolah lebih disulkai oleh } \\
\text { wisataman. }\end{array}$ & 0,12 & 3 & 0,36 \\
\hline 4 & $\begin{array}{l}\text { Harga yang ditawarkan cocol untulk } \\
\text { semua kalangan dari pelajar, } \\
\text { mahasiswa hingga pelkeja }\end{array}$ & 0,10 & 3 & 0,30 \\
\hline 5 & $\begin{array}{l}\text { Delkorasi yang unik menupakan hal } \\
\text { yang paling diminati wisatawan. }\end{array}$ & 0,15 & 4 & 0,60 \\
\hline 6 & $\begin{array}{l}\text { Aksas untul rumah makan yang } \\
\text { berada di Kaswasn Bogor Utara } \\
\text { sangat strategis. }\end{array}$ & 0,10 & 3 & 0,30 \\
\hline & Jumlah Skor Kekuatan & & & 2,15 \\
\hline & b. Faktor Kelemahan (Weakness) & & & \\
\hline 1 & $\begin{array}{l}\text { SDM yang terbastas dalam bisnis } \\
\text { numah maksan. }\end{array}$ & 0,11 & -4 & $-0,44$ \\
\hline 2 & $\begin{array}{l}\text { Kurangnya pengetahuan dalam } \\
\text { bideng gervice pada pegarvai }\end{array}$ & 0,09 & -3 & $-0,27$ \\
\hline 3 & $\begin{array}{l}\text { Fasilitas lahen parkir den Musolah } \\
\text { yeng lurang diperhatikan. }\end{array}$ & 0,10 & -2 & $-0,20$ \\
\hline & Jumlah Skor Kelemahan & & & $-0,91$ \\
\hline & Total & 1,00 & & \\
\hline
\end{tabular}

Sumber : Hasil Penelitian, 2018

Tabel 4 EFE (Eksternal Factor Evaluation)

\begin{tabular}{|c|c|c|c|c|}
\hline No & Faktor Eksternal & Bobot & Rating & Skor \\
\hline \multicolumn{5}{|c|}{ a. Peluang (Opportunities) } \\
\hline I & $\begin{array}{l}\text { Berada di Kawasan Jalur Merah: } \\
\text { (Jalur Perdagangan). }\end{array}$ & 0,20 & 4 & 0.80 \\
\hline 2 & $\begin{array}{l}\text { Sebagai Kawasan wisata kuliner } \\
\text { terbesar di Kota Bogor }\end{array}$ & 0,17 & 3 & 0,51 \\
\hline 3 & $\begin{array}{l}\text { Menjadi rekoméndasi tempat di: } \\
\text { sosial media. }\end{array}$ & 0,16 & 2 & 0,32 \\
\hline & $\begin{array}{l}\text { Jumlah Skor Peluang } \\
\text { b Faktor Ancaman (Threats) }\end{array}$ & & & 1,63 \\
\hline 1 & $\begin{array}{l}\text { Harga bahan . baku yang } \\
\text { digunakan semákin tinggi: }\end{array}$ & 0,18 & -2 & $-0,36$ \\
\hline 2 & $\begin{array}{l}\text { Tumbuhinya kawasan sejenis: } \\
\text { seperti di (Depok Kawasàn } \\
\text { Margonda). }\end{array}$ & 0,15 & -2 & $-0,30$ \\
\hline 3 & $\begin{array}{l}\text { Kemacetan lalu lintas pada saat } \\
\text { alkhir pekan. }\end{array}$ & 0,14 & -3 & $-0,42$ \\
\hline & Jumlah Skor Ancaman (Threats) & & & 1,08 \\
\hline & Total & 1,00 & & \\
\hline
\end{tabular}

Sumber : Hasil Penelitian, 2018 
Berdasarkan perhitungan pada hasil pembobotan Matriks IFE dan EFE, bahwa nilai penjumlahan rata-rata faktor internal adalah Kekuatan $(2,15)$ dan kelemahan(-0,91), yaitu 1,24 (positif). Sedangkan nilai penjumlahan faktor eksternal adalah Peluang $(1,63)$ dan Ancaman (-1,08), yaitu 0,55 (positif). Hasil dari perhitungan tersebut dapat terlihat bahwa Kawasan kuliner Bogor Utara memiliki Kekuatan yang lebih dominan dibanding Kelemahan, dan memiliki Peluang yang lebih besar dibanding Ancaman. Selanjutnya nilai tersebut dimasukan dalam Matriks Grand Strategy.

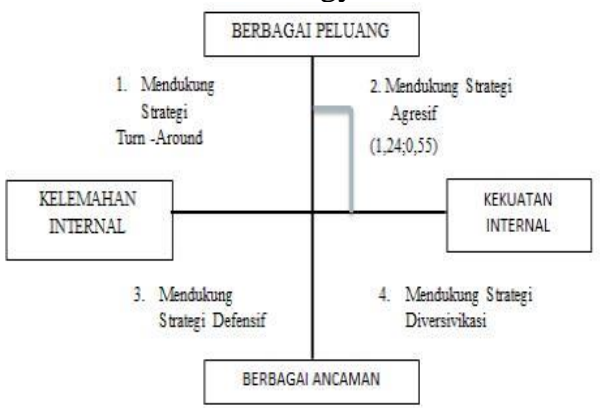

Gambar 9 Matrix Grand Strategy

Pada Matriks Grand Strategyposisi Kawasan Bogor Utara Berada pada koordinat $(1,24 ; 0,55)$ yaitu pada kuadran II. Pada posisi ini kawasan kuliner Bogor Utara berada pada situasi yang menguntungkan. Kawasan ini memiliki kekuatan dan peluang yang cukup tinggi. Dengan hal itu Kawasan Bogor Utara dapat lebih memaksimalakan peluang dan kekuatan yang ada untuk menciptakan kawasan wisata kuliner yang lebih dikenal oleh wisatawan baik yang berdomisili di Bogor ataupun di luar pulau. Kawasan kuliner Bogor Utara memiliki kekuatan dan peluang yang cukup kuat. Setelah melakukan pembobotan dan titik kuadran maka selanjutnya perumusan Strategi Matriks SWOT seperti, SO, ST, WT, WO. Disusun berdasarkan faktor internal (S) dan (W), serta faktor eksternal (O) dan (T).

Tabel 6 Matrix SWOT

\begin{tabular}{|c|c|c|}
\hline & $\begin{array}{c}\text { STRENGTH+ } \\
\text { OPPORTUNITIES } \\
\text { So }\end{array}$ & $\begin{array}{l}\text { STRENGTH+ } \\
\text { WEAKNESS } \\
\text { SW }\end{array}$ \\
\hline $\begin{array}{l}\text { OPPORTUNITIES+ } \\
\text { WEAKNESS } \\
\text { OW }\end{array}$ & $\begin{array}{l}\text { Membuat } \\
\text { inovasi terbaru } \\
\text { dari segi menu, } \\
\text { strategi produksi } \\
\text { makanan, } \\
\text { pelayanan,harga } \\
\text {, dan dekorasi } \\
\text { agar lebih } \\
\text { banyak } \\
\text { wisatawan yang } \\
\text { mengetahui } \\
\text { tentang kawasan } \\
\text { kuliner Bogor }\end{array}$ & $\begin{array}{l}\text { Sebagai } \\
\text { kawasan yang } \\
\text { di rekomendasi } \\
\text { kan melalui } \\
\text { sosial media, } \\
\text { berbagai rumah } \\
\text { makan perlu } \\
\text { memperhatikan } \\
\text { fasilitas- } \\
\text { fasilitas yang } \\
\text { ada. }\end{array}$ \\
\hline
\end{tabular}

\begin{tabular}{|c|c|c|}
\hline & $\begin{array}{l}\text { Utara dengan } \\
\text { memanfaatkan } \\
\text { kawasan yang } \\
\text { berada di jalur } \\
\text { merah. }\end{array}$ & \\
\hline $\begin{array}{c}\text { THREATS+WEAKNES } \\
\text { S } \\
\text { WT }\end{array}$ & $\begin{array}{ll}\text { Membuat } \\
\text { inovasi } \\
\text { menu yang } \\
\text { baru yang } \\
\text { dapat } \\
\text { menyesuaika } \\
\text { n dengan } \\
\text { harga bahan } \\
\text { baku yang } \\
\text { tidak stabill. } \\
\text { Membuat ciri } \\
\text { Khas pada } \\
\text { kawasan } \\
\text { kuliner Kota } \\
\text { Bogor agar } \\
\text { tetap lebih } \\
\text { dikenal } \\
\text { dibanding } \\
\text { kawasan } \\
\text { kuliner } \\
\text { lainnya. }\end{array}$ & \begin{tabular}{lr}
\multicolumn{2}{l}{ Memperhatika } \\
$\mathrm{n}$ & segala \\
fasilitas & agar \\
tidak & kalah \\
menarik & \\
perhatian & oleh \\
kawasan & \\
kuliner & \\
lainnya. &
\end{tabular} \\
\hline
\end{tabular}

Sumber : Hasil Penelitian, 2018

Strategi pengembanga Kawasan Kuliner Bogor Utara Berdasarkan hasil pembobotan dan perhitungan sesuai dengan analisis matriks SWOT dapat dilihat dari Matriks Grand Strategy, Strategi Pengembangan Kawasan Wisata Kuliner Bogor Utara berada di Kuadran II yang merupakan pertemuan dua elemen yaitu kekuatan dan peluang sehingga dapat memanfaatkan dan menciptakan kawasan wisata kuliner yang lebih dikenal baik wisatawan yang berdomisili di Jabodetabek maupun diluar pulau. Kawasan kuliner Bogor Utara memiliki kekuatan dan peluang yang cukup kuat. Maka strategi SO yang harus di terapkan adalah sebagai berikut:

Membuat inovasi terbaru dari segi menu, strategi produksi makanan, pelayanan,harga, dan dekorasi agar lebih banyak wisatawan yang mengetahui tentang kawasan kuliner Bogor Utara dengan memanfaatkan kawasan yang berada di jalur merah atau berada di kawasan khusus perdagangan.

Rekomendasi Perencanaan Pengembangan Kawasan Bogor Utara Berdasarkan Konsep Wisata Kuliner berdasarkan dari hasil analisa yang didapatkan, maka rekomendasi perencanaan pengembangan kawasan Bogor Utara berdasarkan konsep wisata kuliner adalah:

1. Menu

Inovasi atau variasi pada menu di rumah makan memang seharusnya selalu dibuat sesuatu hal yang baru dan lebih menarik perahatian wisatawan yang akan datang. Akan lebih baik apabila rumah makan yang memang tidak dikonsepkan dengan rumah makan tradisional atau khas 
nusantara tersebut tetap menyediakan makanan yang cocok untuk dinikmati oleh semua selera wisatawan.

Sehingga wisatawan tetap dapat merasakan hidangan yang sesuai dengan lidah masingmasing wisatawan dan dapat merasakan suasana rumah makan yang memang ingin dituju.

2. Strategi Produksi Makanan

Membuat inovasi pada Produksi Makanan dalam artian buatlah sesuatu yang berbeda pada cara penyajiannya dengan jenis masakan tersebut. Dan dikemas dengan berbagai hal menarik

agar wisatawan dapat mempertimbangkan strategi produksi makanan sebagai hal yang perlu dipertimbangkan.

3. Pelayanan

Inovasi pada pelayanan lebih diperhatikan antara lain jenis pelayanan yang memang lebih diminati wisatawan antara Self Service, Waiter or Waitress to Table, Counter Service, Automatic Vending. Lalu menggunakan seragam yang disesuaikan dengan tema restoran agar menjadi suatu bagian yang unik pada masing-masing rumah makan yang berada di Kawasan Bogor Utara.

4. Harga

Inovasi harga yang ditawarkan lebih ke arah promo harga seperti dibuatnya diskon atau harga khusus untuk wisatawan yang berkunjung dengan keadaan sedang berulang tahun, atau dibuat setiap rumah makan potongan harga untuk mahasiswa, atau dibuatkan paket untuk acara dengan harga khusus.

5. Dekorasi/ Suasana Ruang

Pada saat ini dekorasi merupakan suatu hal yang memang sangat dilihat apabila wisatawan hendak mengunjungi atau memilih rumah makan. Maka dari itu pengelola harus membuat inovasi terbaru terhadap dekorasi yang berada di rumah makan tersebut. Dalam contoh: apabila rumah makan tersebut mengangkat tema pepohonan atau tumbuhan maka pada musim tertentu ditambahkan ornamern yang berbeda yang mencirikan suasan atau musim yang sedang berlangsung.

\section{SIMPULAN}

Pariwisata Kota Bogor saat ini sedang berada pada tahap berkembang. Salah satunya yang cukup terlihat adalah perkembangan wisata kuliner yang semakin menjamur di Kawasan Bogor. Khususnya pada Kawasan Bogor Utara yang merupakan kawasan terbesar yang ada di Kota Bogor. Terdapat banyak rumah makan yang ada dikawasan ini akan tetapi wisatawan memiliki minat yang cukup tinggi terhadap Lemongrass
Resto hal tersebut dapat dilihat dari hasil perhitungan secara ilmiah menggunakana analisi AHP.

Kawasan Kuliner Bogor Utara ini merupakan kawasan yang memiliki kekuatan dan peluang yang cukup dominan. Kekuatan tersebut seperti Menu, Strategi Produksi Makanan, Pelayanan, Harga, dan Dekorasi. Untuk peluang Kawasan Bogor Utara merupakan kawasan yang dilewati oleh jalur merah yang memiliki arti jalur perdagangan dimana pengusaha bebas membangun usaha disepanjang jalur tersebut. Walaupun kawasan ini memiliki kekuatan dan peluang yang tinggi akan tetapi tetap dibutuhkan pengembangan dengan memaksimalkan kekuatan dan peluang yang ada

\section{DAFTAR PUSTAKA}

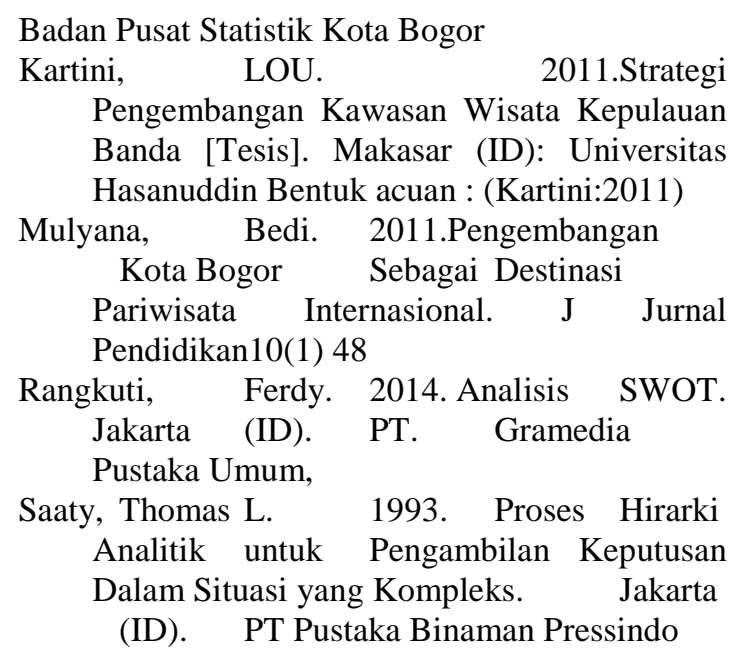

